\title{
Development of a Low-Cost Adsorbent Obtained from Moringa Oleifera and Functionalized with Iron Nanoparticles for Removal of Oil from Produced Water
}

\author{
Tayanara Menezes Santos 1,*iD, Jose Valdo da Silva ², Gabriel Francisco da Silva 2, Luiz Antônio \\ Magalhães Pontes 1

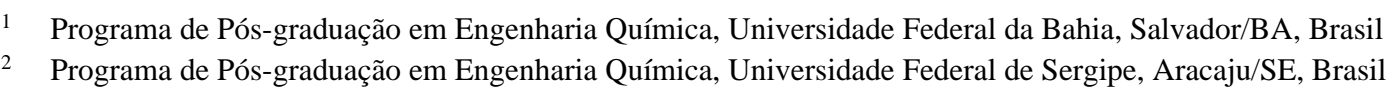

Scopus Author ID 57204038466

Received: 6.01.2021; Revised: 1.02.2021; Accepted: 3.02.2021; Published: 8.02.2021

\begin{abstract}
An activated carbon was developed from Moringa oleifera seed and modified with iron nanoparticles (AC-Fe) for application in the oils and greases $(\mathrm{O} \& \mathrm{G})$ adsorption of the produced water. Activated carbon was prepared by pyrolysis and chemical activation using $\mathrm{NaOH}$. Surface modification was performed by the wet impregnation method. AC-Fe was characterized by scanning electron microscopy (SEM), Brunauer-Emmett-Teller surface area analyzer (BET), X-ray diffraction (XRD), Fourier transform infrared spectroscopy (FTIR), Boehm titration, and point of zero charge ( $\mathrm{pH}_{\mathrm{PZC}}$ ). The amount of $\mathrm{O} \& \mathrm{G}$ adsorbed on $\mathrm{AC}-\mathrm{Fe}$ was sensitive to $\mathrm{pH}$, initial concentration and temperature, but independent of ionic strength. Freundlich isotherm adjusted well, confirming the heterogeneous distribution of active sites and multilayer. The pseudo-second-order kinetic model accurately represents the $\mathrm{O} \& \mathrm{G}$ adsorption process by AC-Fe. Under different temperatures, the maximum amount of O\&G adsorption in AC-Fe calculated by the pseudo-second-order kinetic model was $121.95 \mathrm{mg} \mathrm{g}^{-1}$ (298 K), $111.11 \mathrm{mg} \mathrm{g}^{-1}(303 \mathrm{~K})$, and $106.38 \mathrm{mg} \mathrm{g}^{-1}(308 \mathrm{~K})$. This high adsorption capacity demonstrates the new material potential as a low-cost adsorbent for O\&G removal.
\end{abstract}

Keywords: Moringa oleifera; biomass; activated carbon; modified surface; adsorption; produced water.

(C) 2021 by the authors. This article is an open-access article distributed under the terms and conditions of the Creative Commons Attribution (CC BY) license (https://creativecommons.org/licenses/by/4.0/).

\section{Introduction}

The produced water (PW) in oil fields is the largest effluent generated during oil and natural gas extraction operations. Around 250 million PW barrels are extracted worldwide, being $40 \%$ discarded in the environment [1]. The PW contains different organic and inorganic materials, including oils and greases $(\mathrm{O} \& \mathrm{G})$, minerals, heavy metals, and dispersed solids. Substances typically classified as O\&G include especially hydrocarbons and fatty acids, which Pintor et al. (2016) [2] consider one of the most complicated pollutants to remove from wastewater in oil processing, being able to cause major impacts. Even the thinnest layer of oil affects aquatic life, decreasing the light penetration and the oxygen transfer between air and water, threatening the ecosystem $[3,4]$. For this reason, O\&G limits on PW discharge in oil processing are imposed by environmental law in most countries. In Brazil, the National Council for the Environment (CONAMA) establishes, through Resolution 393 from 2007, that the 
disposal of PW must comply with the simple monthly arithmetic concentration of oils and greases (TOG) up to $29 \mathrm{mg} \mathrm{L}^{-1}$, with a maximum daily value of $42 \mathrm{mg} \mathrm{L}^{-1}$ [5].

Several technologies, separate or integrated, have been used for the PW treatment, coagulation or electrocoagulation, flotation, chemical/electrochemical oxidation, nanofiltration, adsorption, biological treatment, heat process, among others [3,6-14]. However, most of these technologies face high-cost problems, low efficiency, or large occupation areas [9]. Among these techniques, adsorption is considered one of the most promising technologies due to its easy operation, high efficiency, and economic advantages [15]. Another advantage of the adsorption process is the possibility of adsorbent regeneration and oil recovery.

Activated carbon (AC) is recognized as the most used adsorbent in the water and effluents treatment due to its low cost and large adsorption capacity, especially organic compounds. It is a carbon-based material with a large surface area, an internal porous structure with a variable pore distribution, and a broad spectrum of oxygenated functional groups [1619]. Its adsorption capacity is affected by the physical properties and the pores structure, and its chemical properties [15]. According to Bhatnagar et al. (2013) [20], oxygen, hydrogen, sulfur, and nitrogen are generally present in $\mathrm{AC}$ in the form of functional groups and/or atoms chemically attached to the structure. In the carbon structure, the main functional groups that are generally considered responsible for pollutant adsorption include carboxyl, carbonyl, phenols, lactone, and quinones. These functional groups can significantly influence the AC adsorption capacity.

Any carbonic material such as petroleum, wood, coal, or lignite waste can be used for AC production. However, these materials are expensive and/or non-renewable [19,21]. Recently, the use of biomass as a raw material for AC production has become a promising approach because it reduces cost and is more available. In recent times, the precursors used to synthesize various carbon porous materials have been coconut shell [22], Bulgarian peach [23], palm bark [24], corn cob, wheat bran, rice husk, soybean husk [25], buckwheat husks [26], sugarcane bagasse [27], Acacia erioloba pod [28], sunflower seed [29], cassava stem [30], among others. More recently, Santos et al. (2020) [31] produced porous carbon from the Moringa oleifera pod and seed, an adaptable plant in tropical countries, resistant to water crises and productive during the whole year. The coal produced removed $87.2 \%$ of the oils present in the PW but only reached the equilibrium after $4 \mathrm{~h}$.

Currently, there are many studies on chemical modification on the AC surface, and the adsorptive contribution of these changes in surface characteristics was very important $[15,20]$. According to literature reports, AC impregnated with metals has been widely used to enable the formation of active catalytic sites [15,32-36]. Tsoncheva et al. (2015) [36] showed that ACs derived from various agricultural wastes could be adequate support of iron-based catalysts for methanol decomposition. Cheng et al. (2018) [33] prepared an AC and modified its surface with iron and cério to remove methylene blue from effluent. Compared to the initial AC, the maximum monolayer adsorption capacity was increased by $27.31 \%$. Hassan et al. (2017) [34] produced AC from flamboyant pods and impregnated it with iron to remove diazinon from the water. The iron-modified AC adsorption capacity was approximately three times higher than the unmodified AC. Besides, the first presented a more acidic nature. Iron-based materials have been reported to have advantages in cost, chemical stability, and environmental consequences [37].

Although many studies have been dedicated to preparing and synthesizing various types of highly effective adsorbents, there is no iron-modified AC for PW oil removal in the 
literature. In this context, this work developed modified AC with iron nanoparticles from the Moringa oleifera seed, applying it as an adsorbent for O\&G removal. Adsorption isotherms and kinetics were also studied to derive thermodynamic and mass-transport parameters, fundamental for the design of a large-scale adsorption unit.

\section{Materials and Methods}

\subsection{Materials.}

Sodium hydroxide $(\mathrm{NaOH})$, sodium chloride $(\mathrm{NaCl})$, hydrochloric acid $(\mathrm{HCl})$, and iron nitrate III, acquired from Vetec Co., Ltd, Brazil, were used as reagents in this study. The PW model used in the kinetic experiments was prepared in the laboratory from crude oil and sodium chloride to obtain the initial concentrations of $300 \mathrm{mg} \mathrm{L}^{-1}$ and $10000 \mathrm{mg} \mathrm{L}^{-1}$. Crude oil originates from the basin located in Sergipe and Alagoas's states and supplied by an oil explorer. Moringa oleifera seeds were collected in Aracaju, Sergipe.

\subsection{Preparation of adsorbent.}

The AC was produced from the Moringa oleifera seed. The AC synthesis was performed according to the method previously reported [31], with some adaptations. By mechanical extraction, the oil contained inside the seeds has been removed. Then, the seeds were crushed, washed, and dried in an oven at $383 \mathrm{~K}$ for $12 \mathrm{~h}$. The powder obtained from the moringa seed was sieved and separated so that the biomass presented $35 \mathrm{MESH}$ as standard granulometry. The biomass was then pyrolyzed at $873 \mathrm{~K}$ with a nitrogen flow of $5 \mathrm{~mL} \mathrm{~min}{ }^{-1}$ using a laboratory-scale stainless steel reactor. The pyrolysis time was $50 \mathrm{~min}$ (after the reactor reached pyrolysis temperature) and constant heating rate $30{ }^{\circ} \mathrm{C} \mathrm{min}{ }^{-1}$. The reactor is heated with a heating blanket. The temperature is checked using a K-type thermocouple located inside the reactor. The obtained carbon was left in contact with a $1 \mathrm{M} \mathrm{NaOH}$ solution for $120 \mathrm{~min}$ for chemical activation, being magnetically agitated and dried at $378 \mathrm{~K}$ for $4 \mathrm{~h}$. It was then heated to the temperature of $873 \mathrm{~K}$, being kept for $60 \mathrm{~min}$. After cooling, it was washed with $\mathrm{HCl} 0.1$ $\mathrm{M}$ solution until it reaches $\mathrm{pH} 7.0$ to eliminate activating agent residues and other inorganic species formed during the process. In the washing step, the carbon was separated using a membrane filter [31]. The carbon obtained was dried at $378 \mathrm{~K}$ until complete drying and kept in a closed container. This carbon produced was then modified by a metallic salt solution, by the wet impregnation method [15]. The $\mathrm{AC}$ was placed in a solution of $0.05 \mathrm{~mol} \mathrm{~L}{ }^{-1} \mathrm{Fe}\left(\mathrm{NO}_{3}\right)_{3}$ in the proportion of $1 \mathrm{~g} / 20 \mathrm{~mL}$. Then the mixture was magnetically stirred at room temperature for $24 \mathrm{~h}$. The modified AC was washed with deionized water until the supernatant $\mathrm{pH}$ reached 7. It was then dried at $378 \mathrm{~K}$ for $24 \mathrm{~h}$ and marked as AC-Fe.

\subsection{Physicochemical characterization.}

The powder diffraction data of the materials were collected using a Bruker X-ray powder diffractometer (XRD), equipped with a $\mathrm{Cu}$ tube operating at $30 \mathrm{kV}$ and $30 \mathrm{~mA}$. The analyses were performed with $\mathrm{CuK} \alpha$ radiation, step size of $0.02^{\circ}$, and counting time of $2 \% \mathrm{~min}$. The analysis of the sample consisted of data collection in the range of 5 to $70^{\circ} 2 \theta$. The adsorbent's distribution and structure were examined by a field emission scanning electron microscope (SEM) using the Hitachi TM 3000 model equipment, operating with an acceleration voltage of $5 \mathrm{kV}$, filament current of $1850 \mathrm{~mA}$ under high vacuum. Nitrogen 
adsorption-desorption isotherms at $77 \mathrm{~K}$ were measured using MicrotracBEL equipment. An automatic physical adsorption analyzer, ASAP 2020 HD88, produced by Micromeritics, Inc. was used to detect the pore diameter and specific surface area (SBET), using the BET method.

The functional groups of the surface were determined by FTIR spectroscopy, using the Shimadzu equipment, model IRPrestige-21, and Boehm titration. The surface functional groups were determined using a modification of the Boehm titration method: 1 gram of each activated carbon sample was immersed in different vials containing $50 \mathrm{~mL}$ of $0.05 \mathrm{M}$ solutions of $\mathrm{HCl}, \mathrm{NaOH}, \mathrm{NaHCO}_{3}$, or $\mathrm{Na}_{2} \mathrm{CO}_{3}$. The sample was agitated under nitrogen atmosphere to remove atmospheric $\mathrm{CO}_{2}$; then, $10 \mathrm{~mL}$ of each solution were potentiometrically titrated with $\mathrm{HCl}$ or $\mathrm{NaOH} 0.05 \mathrm{M}$ previously standardized for basic and acidic solutions, respectively $[38,39]$. The $\mathrm{pH}$ of the point of zero charges $\left(\mathrm{pH}_{\mathrm{pzc}}\right)$ was estimated according to the method described by Mueller et al. (1980) [40].

\subsection{Adsorption experiments.}

Adsorption tests were conducted under different conditions, mixing a known dosage of adsorbent $\left(2.5 \mathrm{~g} \mathrm{~L}^{-1}\right)$ with $200 \mathrm{~mL}$ of model PW. The tests were performed for $4 \mathrm{~h}$ at a controlled temperature under the agitation of $200 \mathrm{rpm}$. The ionic force effect was analyzed using different $\mathrm{NaCl}$ concentrations $\left(0-20 \mathrm{~g} \mathrm{~L}^{-1}\right)$. To observe the effect of $\mathrm{pH}$, experiments were carried out at $\mathrm{pH} \mathrm{4,5,6,7,8,} \mathrm{and} \mathrm{9.} \mathrm{For} \mathrm{adsorption} \mathrm{isotherms,} \mathrm{the} \mathrm{initial} \mathrm{concentration} \mathrm{of} \mathrm{O \& G} \mathrm{(100-}$ $\left.500 \mathrm{mg} \mathrm{L}^{-1}\right)$ and temperature $(298,308$, and $318 \mathrm{~K}$ ) were varied. At pre-established time intervals, the spare samples were collected, and TOG analysis was performed. The tests were performed in triplicate.

The adsorption capacity in equilibrium is calculated by Eq. (1):

$\mathrm{q}_{\mathrm{e}}=\mathrm{V}\left(\mathrm{C}_{0}-\mathrm{C}_{\mathrm{e}}\right) / \mathrm{m}$

where $\mathrm{q}_{\mathrm{e}}$ is the adsorption capacity in the balance of activated carbon $\left(\mathrm{mg} \mathrm{g}^{-1}\right), \mathrm{V}$ is the volume of the solution (L), $\mathrm{C}_{0}$ is the initial concentration of oils and greases $\left(\mathrm{mg} \mathrm{L}^{-1}\right), \mathrm{C}_{\mathrm{e}}$ is the concentration of oils and greases in equilibrium $\left(\mathrm{mg} \mathrm{L}^{-1}\right)$ and $\mathrm{m}$ is the amount of activated carbon $(\mathrm{g})$.

Spectro Scientific's Infracal oil and grease analyzer was used to determine the O\&G concentration. The analyzer works by infrared absorption spectrometry.

\subsection{Desorption and regeneration.}

The desorption experiment examined the potentiality of the adsorbent to be regenerated. AC-Fe samples obtained from adsorption experiments were collected by centrifugation and filtration. An amount of activated carbon loaded with $\mathrm{O} \& \mathrm{G}$ was desorbed using distilled water and $\mathrm{HCl} 0.1 \mathrm{M}$ solution. Then, the regenerated adsorbent was completely dried [41-43]. For reuse studies, regenerated adsorbent $\left(0.25 \mathrm{~g} \mathrm{~L}^{-1}\right)$ was mixed with $200 \mathrm{~mL}$ of O\&G solution $\left(300 \mathrm{mg} \mathrm{L}^{-1}\right)$ at $298 \mathrm{~K}$. This adsorption-desorption cycle was performed three times.

\section{Results and Discussion}

\subsection{Characterization of the activated carbon.}

The configuration of the surface functional groups is considered an important factor in determining activated carbon's adsorption behavior. The FTIR spectra can characterize the surface functional groups of carbons. As shown in Figure 1, the AC and AC-Fe spectra 
presented similar peaks, indicating chemical composition with differences in the modified AC's surface. There are functional groups, such as the elongation vibration around $3400 \mathrm{~cm}^{-1}$ in the two materials. This peak can be attributed to the elongation of the hydroxyl groups' vibrations but indicating water presence and the carboxylic or phenolic groups in the materials' structure. Stretching vibration representing aliphatic C-H and group $\mathrm{CH}_{2}$ (around 2880 and $2900 \mathrm{~cm}^{-1}$, respectively), carbonyl group $\mathrm{C}=\mathrm{O}$ (around $\left.1600 \mathrm{~cm}^{-1}\right), \mathrm{C}=\mathrm{C}\left(\right.$ around $\left.1440 \mathrm{~cm}^{-1}\right)$ and phenolic groups (around $1080 \mathrm{~cm}^{-1}$ ) [44-46]. The band close to $600 \mathrm{~cm}^{-1}$ is attributed to the $\mathrm{Fe}-\mathrm{O}$ vibration, indicating that the impregnation occurred and $\mathrm{Fe}-\mathrm{O}$ complexes or iron oxides in the AC-Fe [23,47,48]. According to Anjum et al. (2019) [49], the introduction of these groups on the AC's surface increases the polarity and alters the surface load.

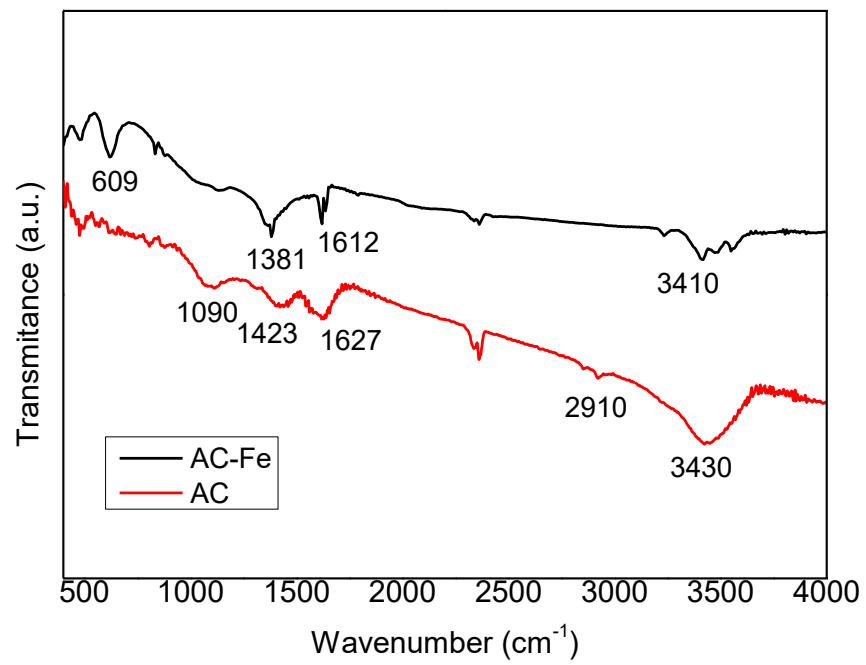

Figure 1. FTIR spectra of the AC and AC-Fe.

The SEM analysis characterized the microstructures of the activated carbons. Figure 2 shows the morphology of the AC surface, before and after activation with $\mathrm{NaOH}$, and of the AC-Fe. It is observed that, without the $\mathrm{NaOH}$ (Figure 2a) activation, the carbon presented porous structures on the surface, caused by devolatilization. However, carbon porosity was still low. With the $\mathrm{NaOH}$ activation, many larger pores were developed on the external coal surface, which favored the development of meso-micropores in the internal surface (Figure 2b). This interconnected meso-micropores structure can promote mass transfer and improve the adsorption capacity of O\&G molecules [44]. However, after impregnation with Fe, the activated carbon surface was peeling and quite rough (Figure 2c), indicating that the metal ions were successfully charged into the activated carbon. The term impregnation is defined as the fine distribution of chemicals and/or metal particles in the AC pores [20].

XRD patterns were used to analyze the crystalline structures of the adsorbents. The Xray diffraction spectra of $\mathrm{AC}$ and $\mathrm{AC}-\mathrm{Fe}$ are shown in Figure 3. The centralized extended signal at $25^{\circ}$ on the $\mathrm{AC}$ diffractogram confirmed amorphous carbon presence, and the signal at $30^{\circ}$ indicates graphitic carbon presence. In the AC-Fe diffractogram, there are signals at $51^{\circ}$ and $75^{\circ}$ that indicate organized carbon presence [50].

Figure 4 shows the results of the $\mathrm{N}_{2}$ physisorption analysis for the materials. The isothermal profile provides truly relevant information about the materials. The $\mathrm{N}_{2}$ adsorption isotherm is widely used for the characterization of surface areas and pore structures. Here, the coals presented type IV isotherms, characteristics of mesoporous materials characterized by hysteresis by desorption, with microporosity [50,51]. 
(a)

(b)
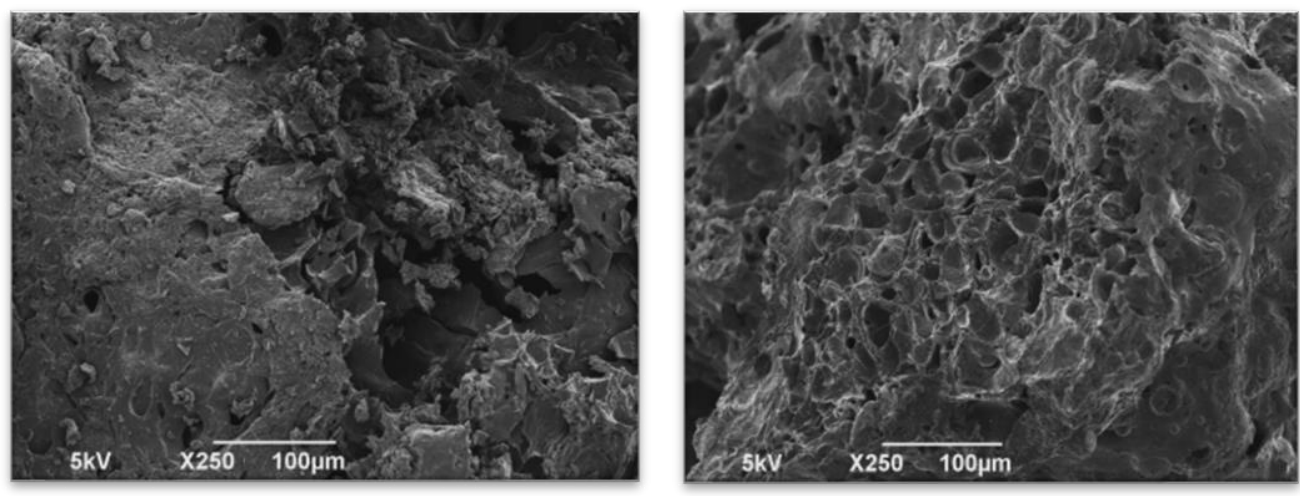

(c)

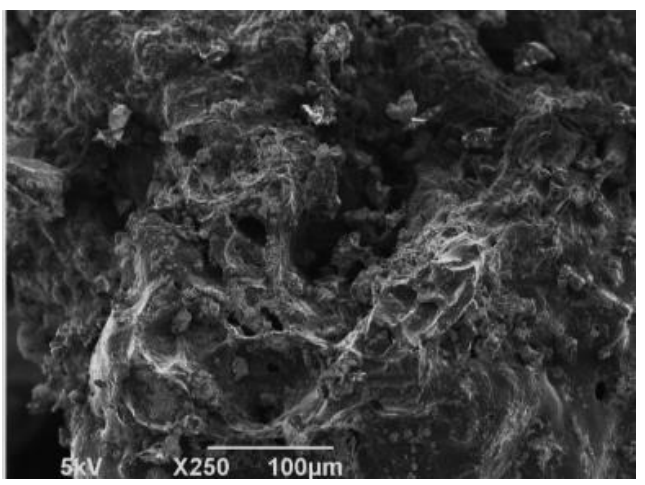

Figure 2. SEM images of the AC (a) before activation; (b) after activation with $\mathrm{NaOH}$; (c) AC-Fe.

(a)

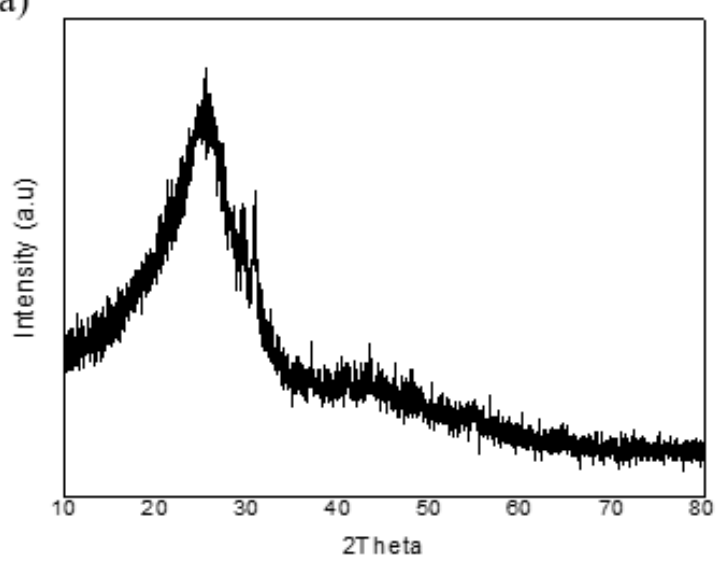

(b)

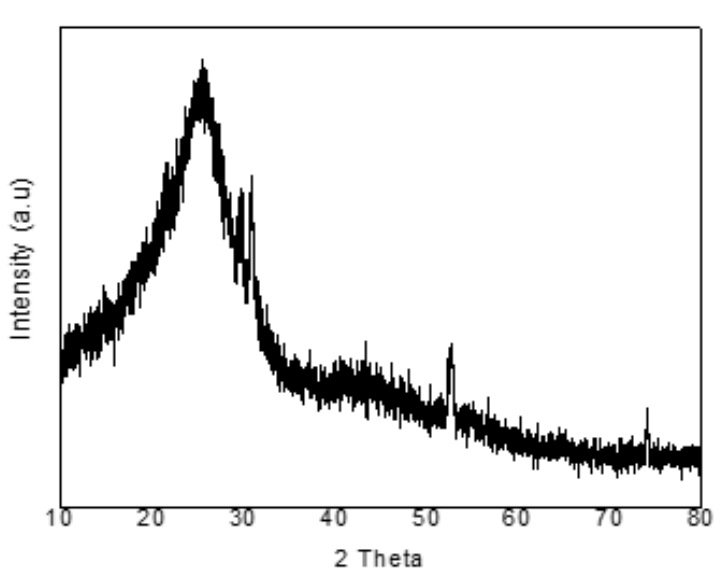

Figure 3. XRD spectra of (a) AC; (b) AC-Fe.

Hysteresis is formed when the desorption curve does not coincide with the isotherm adsorption curve, where the lower line represents the amount of gas adsorbed with increasing pressure and the line above the desorbed gas amount. The hysteresis of these materials is type $\mathrm{H} 4$, which refers to non-homogeneous laminar pores with some interconnectivity. This isothermal profile does not exclude the existence of microporosity, with openings smaller than $20 \AA[50]$. The amount of nitrogen adsorption increases sharply when $\mathrm{P} / \mathrm{P}_{0}>0.80$, indicating that the presence of mesoporous structures is abundant [15]. In addition, the $\mathrm{N}_{2}$ adsorptiondesorption isotherms of the coals show that after the modification, the adsorption of $\mathrm{N}_{2}$ decreased, indicating that the metal blocked some holes in the modified activated carbon $[44,50]$. This can be proven by BET surface area and pore volume. 


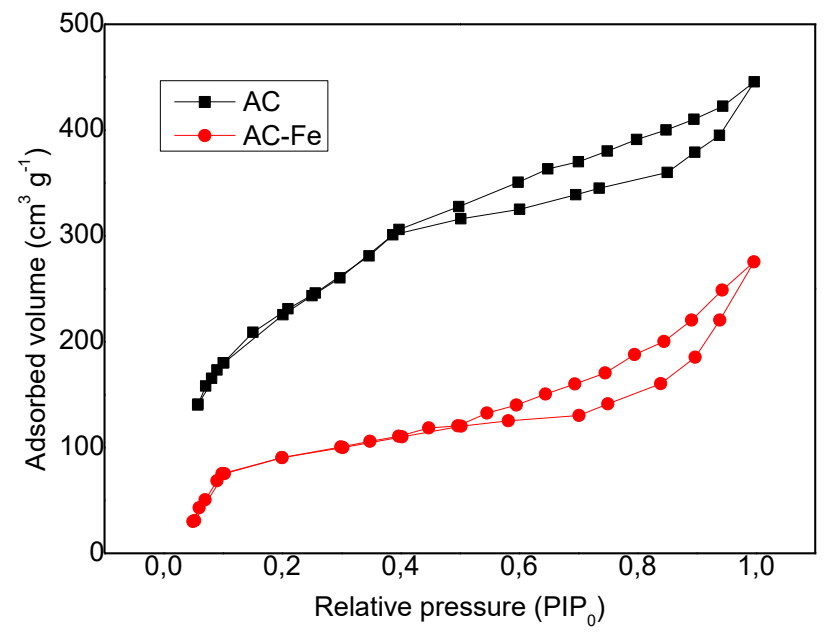

Figure 4. Nitrogen adsorption isotherm of the AC and AC-Fe.

By using the BET method, it was observed that AC-Fe is porous. The AC-Fe reached a specific surface area very close to what was achieved using grape seed, $603 \mathrm{~m}^{2} \mathrm{~g}^{-1}$ [36]. The specific surface area and pore volume for the AC-Fe were $578.4 \mathrm{~m}^{2} \mathrm{~g}^{-1}$ and $0.48 \mathrm{~cm}^{3} \mathrm{~g}^{-1}$. The carbon that Santos et al. (2020) [31] developed from Moringa oleifera had a specific surface area of $660.78 \mathrm{~m}^{2} \mathrm{~g}^{-1}$, about $15 \%$ larger than the AC-Fe produced in this work. A smaller surface area for AC-Fe can be explained, mainly because iron occupies part of the available pores. Besides, part of the mass comprising the material is formed by metallic iron, whose specific surface area is intrinsically low [23,50]. The pore volume determined for the AC-Fe was $0.40 \mathrm{~cm}^{3} \mathrm{~g}^{-1}$. Studies suggest that the volumes of conventional mesoporous activated carbons are in the range of $0.1-0.50 \mathrm{~cm}^{3} \mathrm{~g}^{-1}$, according to the volume determined for AC-Fe [52]. The average pore size of AC-Fe is $3.19 \mathrm{~nm}$, which indicates that carbon is mesoporous due to most pores being in the range of 1 to $4 \mathrm{~nm}$ [33].

The functional group determination of the surface by Boehm titration, Table 1, indicated that the $\mathrm{AC}$ before activation with $\mathrm{NaOH}$ has acidic nature. The acid-base titration results suggest that $\mathrm{NaOH}$ activation added basic functional groups with more positive load, and $\mathrm{AC}$ after $\mathrm{NaOH}$ activation became basic, which was confirmed by $\mathrm{pH}_{\mathrm{pzc}}$ values. Under alkaline solutions, $\mathrm{OH}$ ions are expected to react with the AC surface functional groups [20,53]. According to Bhatnagar et al. (2013) [20], carbon alkaline treatment is beneficial for increasing adsorption of especially organic species, such as phenol, present in PW. Chiang et al. (2002) [54] found that the AC treated with $\mathrm{NaOH}$ showed a significant increase in the concentration of phenolic functional groups on the surface, as also observed in this article. It is also observed in Table 1 that the number of basic groups decreased after AC impregnation with iron. These changes suggested that iron impregnation altered the AC surface, functional groups.

Table 1. Functional surface groups analyzed by Boehm method and point of zero charge.

\begin{tabular}{|c|c|c|c|c|c|c|}
\hline \multirow{2}{*}{ Sample } & \multicolumn{3}{|c|}{ Acidic groups (mmol g-1) } & \multirow{2}{*}{$\begin{array}{c}\text { Basic } \\
\text { groups } \\
\left(\mathbf{m m o l ~ g} \mathbf{g}^{-1}\right)\end{array}$} & \multirow{2}{*}{$\begin{array}{c}\text { Total acidic } \\
\text { groups (mmol } \\
\left.\mathbf{g}^{-1}\right)\end{array}$} & \multirow[b]{2}{*}{$\mathrm{pH}_{\mathrm{pzc}}$} \\
\hline & Carboxylic & Lactones & Phenolics & & & \\
\hline $\begin{array}{c}\text { AC before activation } \\
\text { with } \mathrm{NaOH}\end{array}$ & 0.430 & 0.083 & 0.204 & 0.459 & 0.717 & 5.5 \\
\hline $\begin{array}{c}\mathrm{AC} \text { after } \mathrm{NaOH} \\
\text { activation }\end{array}$ & 0.269 & 0.036 & 0.237 & 0.625 & 0.542 & 8.2 \\
\hline $\mathrm{AC}-\mathrm{Fe}$ & 0.234 & 0.061 & 0.228 & 0.592 & 0.523 & 7.4 \\
\hline
\end{tabular}

The point of zero charges for AC and AC-Fe was determined by the method described by Mueller et al. (1980) [40], resulting em $\mathrm{pH}_{\mathrm{pzc}, \mathrm{AC}}=8.2$ e $\mathrm{pH}_{\mathrm{pzc}}, \mathrm{AC}-\mathrm{Fe}=7.4$. This indicates that 
the AC and AC-Fe surface is positively charged at $\mathrm{pH}$ values below 8.2 and 7.4, respectively. And it is negatively charged at $\mathrm{pH}$ values greater than 8.2 and 7.4 , respectively.

\subsection{Influence of ionic strength on the adsorption of $O \& G$.}

There are many ions in PW; therefore, research on ionic strength effect on the adsorption of O\&G by AC and AC-Fe was carried out. Figure 5 shows O\&G adsorption by AC and AC$\mathrm{Fe}$ at different $\mathrm{NaCl}$ concentrations. As shown, the change in $\mathrm{O} \& \mathrm{G}$ removal rate when $\mathrm{NaCl}$ concentration is increased is not significant. This can happen because $O \& G$ are generally organic macromolecules, and macromolecules cannot easily enter the pores of activated carbon, while most inorganic ions can be adsorbed in the micropores of activated carbon [15]. Besides, the influence of ion competition on adsorption can be considered. Chlorine ions and metal ions in activated carbon would form chlorides to compete with $O \& G$ at adsorption sites. However, it is observed that the adsorptive contribution of impregnation on the AC surface characteristics was important.

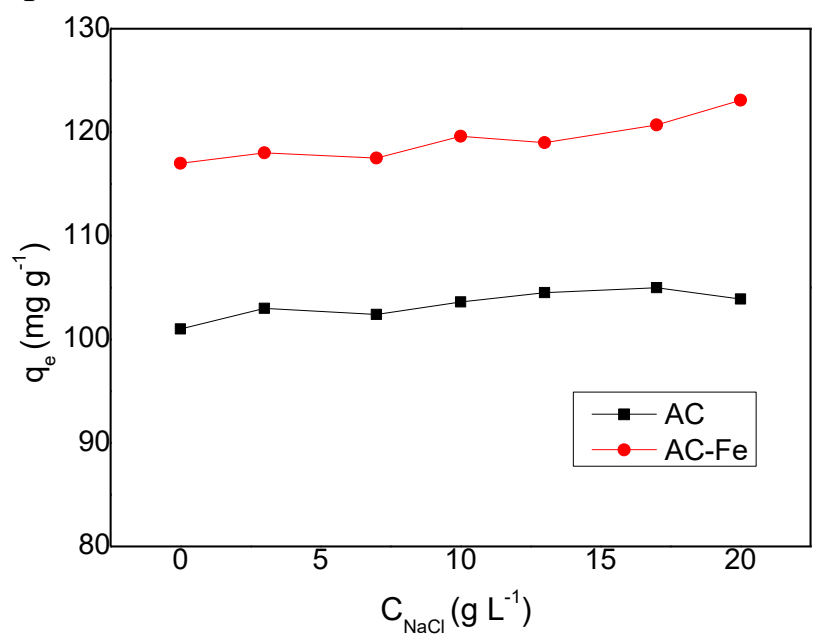

Figure 5. Effect of different ionic strength conditions on the adsorption of O\&G.

\subsection{Influence of $p H$ on the adsorption of $O \& G$.}

The $\mathrm{pH}$ solution is one of the determining factors that control the adsorption capacity of the adsorbent. The O\&G adsorption capacity by $\mathrm{AC}$ and $\mathrm{AC}-\mathrm{Fe}$ as a function of $\mathrm{pH}$ ranging from 4 to 9 is presented in Figure 6. It is observed that the adsorption capacity was practically maintained with the $\mathrm{pH}$ increase, up to 7.0, but an additional increase in $\mathrm{pH}$ led to a lower adsorption capacity in both cases. At $\mathrm{pH}$ between 4 and 7 , the excess proton is in the surface functional groups (protonation), and the surface load becomes positive $\left(\mathrm{pH}<\mathrm{pH}_{\mathrm{pzc}}\right.$ ), the degree of functional groups ionization containing oxygen (carboxylic and hydroxyl groups) increases, which increases the electrostatic attractions between $\mathrm{AC}$ and $\mathrm{AC}-\mathrm{Fe}$ and the molecules that form O\&G. On the other hand, when a proton is removed from the oxygen transport groups (deprotonation), electrostatic repulsions between the negatively charged surface $\left(\mathrm{pH}>\mathrm{pH} \mathrm{pzc}_{\mathrm{pc}}\right.$ of carbons and the O\&G molecules ionic form increase. That is what explains Anjum et al. (2019) [49] in BTX adsorption by modified activated carbon. Besides, several authors agree that the $\mathrm{pH}$ decrease contributes to the emulsion destabilization, resulting in an improvement in oil adsorption in various adsorbent materials. This works even better when the adsorbent also becomes positively charged via surface protonation functionality [2]. 


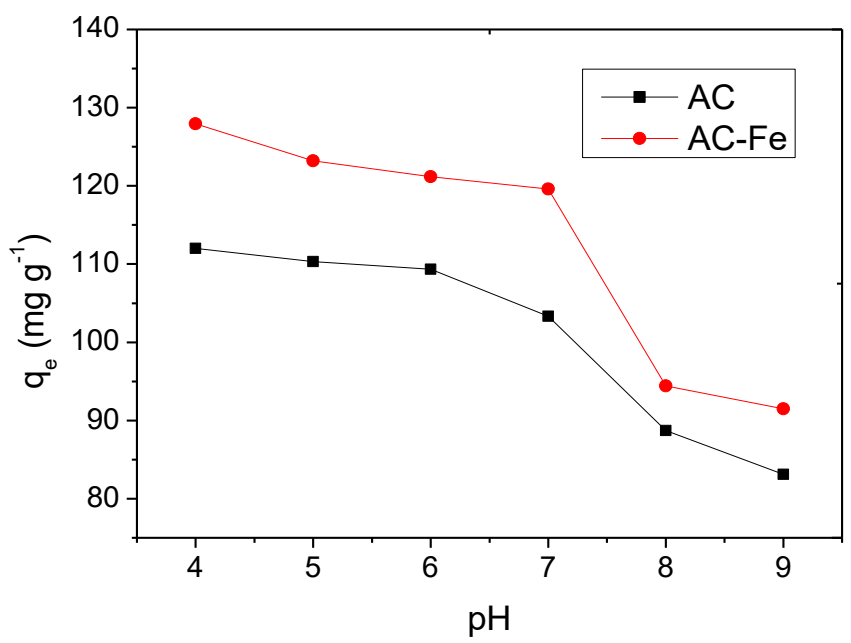

Figure 6. Effect of $\mathrm{pH}$ on the adsorption of $\mathrm{O} \& \mathrm{G}$ in $\mathrm{AC}$ and $\mathrm{AC}-\mathrm{Fe}$ to $\mathrm{T}=298 \mathrm{~K}$, initial concentration of 300 $\mathrm{mg} \mathrm{L}^{-1}$, agitator speed of $200 \mathrm{rpm}$, adsorbent dosage $2.5 \mathrm{~g} \mathrm{~L}^{-1}$, and contact time $360 \mathrm{~min}$.

\subsection{Influence of temperature and initial concentration on adsorption of $O \& G$.}

Figure 7 shows the relationship between $q_{e}$ and $C_{e}$ at three different temperatures. The increasing initial concentration up to $500 \mathrm{mg} \mathrm{L}^{-1}$ resulted in a significant increase in the adsorption capacity. However, Mowla et al. (2013) [55] state that clogging effects may occur if higher oil concentrations are present.
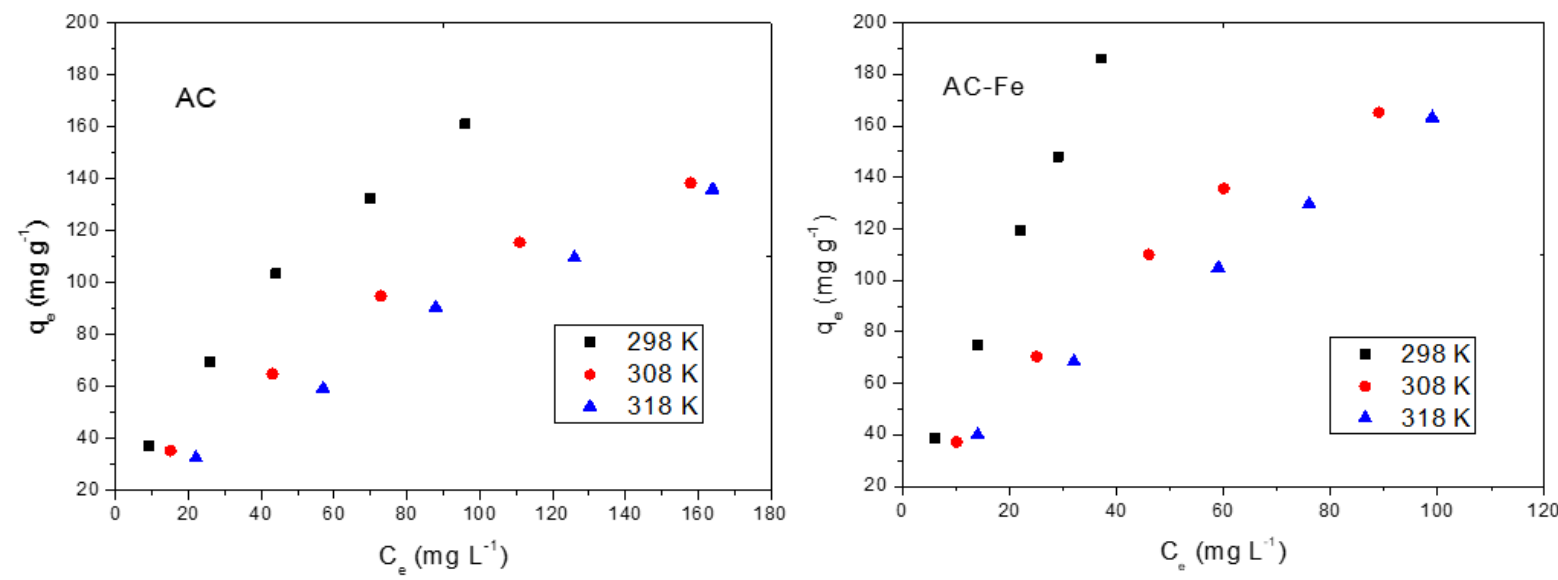

Figure 7. Effect of initial concentration on adsorption of $\mathrm{O} \& \mathrm{G}$ in (a) AC; (b) AC-Fe.

The temperature has two main effects on adsorption. As the temperature of the reaction increases, the solution viscosity reduces. Thus, increasing the diffusion rate of adsorption molecules in the outer boundary layer and the adsorbent particles' internal pores [15]. In addition, as the temperature changes, the specific adsorbed adsorption balance changes. An increase in temperature leads to the chemical-surface composition effect disappearance of activated carbons on adsorption [56]. To investigate the temperature influence on O\&G adsorption by AC-Fe, experiments were carried out at different temperatures $(298 \mathrm{~K}, 308 \mathrm{~K}$, and $318 \mathrm{~K}$ ).

Figure 8 shows how these temperatures influence the $\mathrm{O} \& \mathrm{G}$ removal from $\mathrm{PW}$ to $\mathrm{AC}$ Fe. What is observed is that as the temperature increases, the $O \& G$ adsorption decreases. This phenomenon shows that O\&G adsorption by AC-Fe is an exothermic process. Although high temperatures can accelerate the $O \& G$ diffusion rate in the liquid film and the activated carbon surface voids, the adsorption balance has moved in the reverse direction as the temperature increases. Therefore, as the temperature increased and the equilibrium time decreased, the 
adsorption amount decreased. Thermodynamic calculations can ratify this deduction. Thus, for this adsorption process, lower temperatures make the process more efficient. Besides, Anjum et al. (2019) [49] affirm that higher operating temperatures can result in carbonaceous adsorbent surface degradation. Hu et al. (2017) and Acosta et al. (2018) [15,56] found a similar performance by analyzing the ceftazidime and bisphenol adsorption in activated carbon, respectively. Santos et al. (2020) [31] also observed that the O\&G adsorption in the coal they produced is an exothermic process.

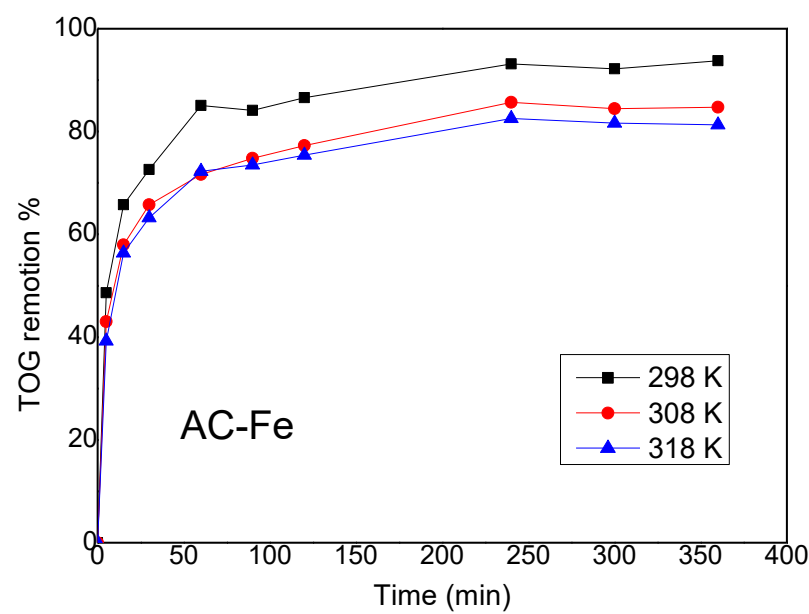

Figure 8. O\&G adsorption in $\mathrm{AC}-\mathrm{Fe}$ at different temperatures.

\subsection{Adsorption kinetics.}

Kinetic experiments were carried out to evaluate the impact of contact time and dynamic characteristics. The kinetic study shows a rapid adsorption process, with balance achieved in 120 min. Figure 9 shows that AC-Fe removes $93.1 \%$ of TOG for the $300 \mathrm{mg} \mathrm{L}^{-1}$ initial concentration. During the initial 5 minutes, the AC-Fe removal rate was $65.7 \%$, which can be considered extremely high. The main reasons for this phenomenon mainly involve the highest driving adsorption force during the initial minutes of the process, with weak resistance to mass transfer and, secondly, due to the high mesopores availability at the beginning of adsorption. Subsequently, it is more difficult to occupy the remaining sites due to the repulsive forces between the O\&G already adsorbed in the adsorbent and those present in the solutions. Also, the molecules are forced to diffuse in micropores by decreasing the pore, leading to a reduction in the removal rate [35]. AC-Fe can then be used to remove a large O\&G percentage in a short contact time.

Three kinetic models were examined to adjust the experimental data: pseudo-firstorder, pseudo-second-order, and intraparticle diffusion model.

The pseudo-first-order model is described by Eq. (2):

$\ln \left(q_{t}-q_{e}\right)=\ln q_{e}-k_{l t}$

The pseudo-second-order model is described by Eq. (3):

$\mathrm{t} / \mathrm{q}_{\mathrm{t}}=1 /\left(\mathrm{k}_{2} \cdot \mathrm{q}_{\mathrm{e}}\right)+\mathrm{t} / \mathrm{q}_{\mathrm{e}}$

The intraparticle diffusion model is described by Eq. (4):

$q_{t}=k_{i} \cdot t^{1 / 2}+C$

Where $\mathrm{q}_{\mathrm{t}}$ is the activated carbon adsorption capacity in time $\mathrm{t}, \mathrm{q}_{\mathrm{e}}\left(\mathrm{mg} \mathrm{g}^{-1}\right)$ is the adsorption capacity in equilibrium, $\mathrm{k}_{1}$ is the constant of the pseudo-first-order rate $\left(\mathrm{min}^{-1}\right), \mathrm{k}_{2}$ is the pseudo-second constant velocity order $\left(\mathrm{g} \mathrm{mg}^{-1} \mathrm{~min}^{-1}\right)$, and $\mathrm{k}_{\mathrm{i}}$ is the intraparticle diffusion constant speed $\left.\left(\mathrm{mg}(\mathrm{g} \mathrm{min})^{0.5}\right)^{-1}\right)$. The experimental data and the regressive results for the three 
models are shown in Figure 9, and the adjusted parameters are shown in Table 2. $\mathrm{R}^{2}$ values show that the pseudo-second-order kinetic model fits better to identify the O\&G kinetic behavior adsorption in AC-Fe. The AC-Fe adsorbed equilibrium load, predicted by the pseudosecond-order model, was well agreed with the experimental value of $119.60 \mathrm{mg} \mathrm{g}^{-1}$ at $298 \mathrm{~K}$.

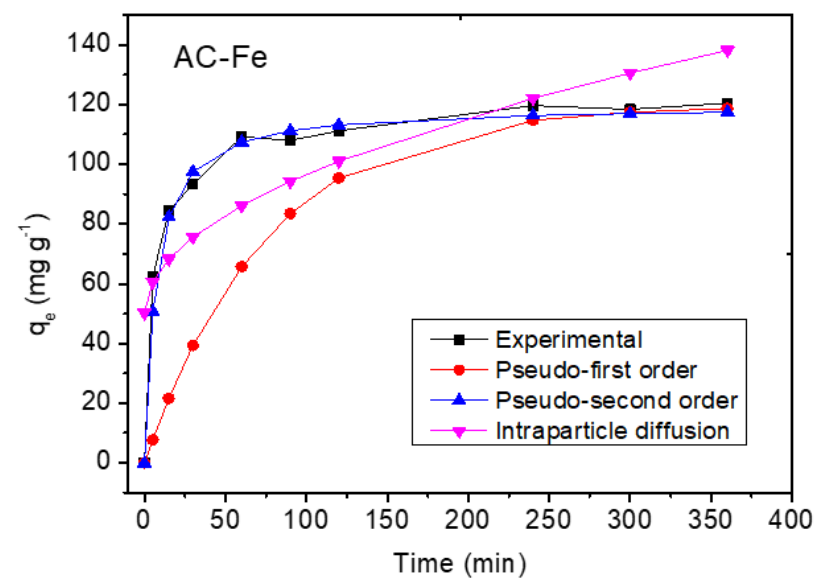

Figure 9. O\&G adsorption experimental data in $\mathrm{AC}-\mathrm{Fe}$ and the pseudo-first-order application, pseudo-secondorder, and intraparticle diffusion models to $\mathrm{T}=298 \mathrm{~K}$, initial concentration $300 \mathrm{mg} \mathrm{L}^{-1}$, agitator speed of 200 $\mathrm{rpm}$, the dosage used $2.5 \mathrm{~g} \mathrm{~L}^{-1}$ and contact time $360 \mathrm{~min}$.

The kinetic velocity constant $\mathrm{k}_{2}$ calculated was $12.27 \times 10^{-4} \mathrm{~g} \mathrm{mg}^{-1} \mathrm{~min}^{-1}$, at $298 \mathrm{~K}$. This constant value was higher than that determined by Santos et al. (2020) [31], 5.63 $\times 10^{-4} \mathrm{~g} \mathrm{mg}^{-1}$ $\min ^{-1}$, for the $\mathrm{O} \& \mathrm{G}$ adsorption in activated carbon based on Moringa oleifera without chemical modification. The difference in $\mathrm{k}_{2}$ between $\mathrm{AC}$ and $\mathrm{AC}-\mathrm{Fe}$ is attributed to the metal ions impregnation process. This indicates that by impregnating $\mathrm{AC}$ with iron, the $\mathrm{O} \& \mathrm{G}$ removal rate has been improved. The results mentioned above indicate that iron impregnation after carbonization plays a significantly important role in distributing pore structure and the surface chemical characteristics, making the $\mathrm{O} \& \mathrm{G}$ removal rate using $\mathrm{AC}-\mathrm{Fe}$ higher than when using AC.

Table 2. Kinetic parameters of pseudo-first-order, pseudo-second-order, and intraparticle diffusion models.

\begin{tabular}{|c|c|c|c|c|c|c|c|c|c|}
\hline \multirow[t]{2}{*}{$\mathbf{T}(\mathbf{K})$} & \multicolumn{4}{|c|}{ Pseudo-first order } & \multicolumn{3}{|c|}{ Pseudo-second order } & \multicolumn{2}{|c|}{$\begin{array}{c}\text { Intraparticle } \\
\text { diffusion }\end{array}$} \\
\hline & $\begin{array}{c}\mathbf{q}_{\mathrm{e}, \text { exp }} \\
\left(\mathbf{m g ~ g}^{-1}\right)\end{array}$ & $\underset{\left(\mathbf{m g ~ g}^{-1}\right)}{\mathbf{q u}_{\mathrm{e}} \text { cal }}$ & $\begin{array}{c}\mathbf{k}_{1} \\
\left(\mathbf{m i n}^{-1}\right)\end{array}$ & $\mathbf{R}^{2}$ & $\begin{array}{c}\mathbf{q e}_{\mathrm{e}, \mathrm{cal}} \\
\left(\mathbf{m g ~ g}^{-1}\right)\end{array}$ & $\begin{array}{c}\mathbf{k}_{2} \\
\left(\mathbf{g ~ m g}^{-1}\right. \\
\left.\text { min }^{-1}\right)\end{array}$ & $\mathbf{R}^{2}$ & $\mathbf{k}_{\mathbf{i}}$ & $\mathbf{R}^{2}$ \\
\hline 298 & 119.60 & 48.33 & 0.0133 & 0.8821 & 121.95 & $12.27 \times 10^{-4}$ & 0.9993 & 4.6314 & 0.6508 \\
\hline 308 & 110.00 & 48.35 & 0.0111 & 0.9393 & 111.11 & $11.09 \times 10^{-4}$ & 0.9987 & 4.3101 & 0.6891 \\
\hline 318 & 106.00 & 42.87 & 0.0107 & 0.8947 & 106.38 & $13.17 \times 10^{-4}$ & 0.9991 & 4.1834 & 0.6765 \\
\hline
\end{tabular}

Several studies have shown that modifying the activated carbon surface can increase the organic compounds adsorption capacity. The modification of commercial activated carbon and carbon fiber activated by the treatment with helium at high temperature or ammonia or impregnation with iron followed by the treatment with high-temperature ammonia was studied by Cheng et al. (2005) [57]. Activated carbons impregnated with iron and treated with ammonia showed significantly higher adsorption of dissolved organic matter than virgin activated carbon. The improved uptake of organic matter dissolved by iron-impregnated activated carbon was suggested due to the carbon surface's iron species presence.

Dastgheib et al. (2004) [58] investigated the iron-activated carbon impregnation to improve the dissolved natural organic matter (DNO) removal from natural waters and reported that iron impregnation followed by high-temperature ammonia treatment increased DNO uptake by about 50-120\%. Bhatnagar et al. (2013) [20] showed that the activated carbon 
impregnation's main advantages include catalytic properties optimization, promoting its integrated catalytic oxidation capacity, and synergism between coal and impregnation agent. Table 3 presents other adsorbents used to remove oil from the aqueous medium.

\begin{tabular}{|c|c|c|c|c|}
\hline Adsorbent & Conditions & $\begin{array}{c}\text { Adsorption } \\
\text { capacity } \\
\left(\mathrm{mg} \mathrm{g}^{-1}\right)\end{array}$ & $\begin{array}{c}\text { Remotion } \\
\%\end{array}$ & References \\
\hline $\begin{array}{lcr}\text { Activated carbon } & \text { from } \\
\text { Moringa oleifera } & \text { seed } \\
\text { impregnated with iron } & \end{array}$ & $\begin{array}{c}\mathrm{C}_{0}: 300 \mathrm{mg} \mathrm{L}^{-1} ; 2.5 \mathrm{~g} \mathrm{~L}^{-1} \text { of } \\
\text { adsorbent; } 298 \mathrm{~K}\end{array}$ & 121.95 & $94,2 \%$ & This work \\
\hline $\begin{array}{l}\text { Iron Oxide/Bentonite Nano } \\
\text { Adsorbents }\end{array}$ & $\mathrm{C}_{0}: 170 \mathrm{mg} \mathrm{L}^{-1}$ & 35.67 & $\begin{array}{l}67 \% \text { after } \\
90 \mathrm{~min}\end{array}$ & [62] \\
\hline Graphene nanoplatelets & $\begin{array}{c}\mathrm{C}_{0}: 200 \mathrm{ppm} ; \mathrm{pH} 6.5 ; 150 \mathrm{rpm} ; \\
3 \mathrm{~g} \mathrm{~L}^{-1} \text { of adsorbent; } 25^{\circ} \mathrm{C}\end{array}$ & 85.00 & $68.5 \%$ & [63] \\
\hline $\begin{array}{l}\text { Zeolitic } \\
\text { framework }\end{array}$ & $\begin{array}{c}\mathrm{C}_{0}: 450 \mathrm{mg} \mathrm{L}^{-1} ; \\
2 \mathrm{mg} \text { of adsorbent; } 20^{\circ} \mathrm{C}\end{array}$ & 3000 & - & [64] \\
\hline Sawdust & $\begin{array}{c}\mathrm{C}_{0}: 1318 \mathrm{mg} \mathrm{L}^{-1} \\
0.2 \mathrm{~g} \text { adsorbent } / 40 \mathrm{~mL} \text { of } \mathrm{PW}\end{array}$ & 33 & - & [65] \\
\hline Palm shell & $\begin{array}{c}\mathrm{C}_{0}: 1404 \mathrm{mg} \mathrm{L}^{-1} \\
4 \mathrm{~g} \text { adsorbent } / 40 \mathrm{~mL} \text { of } \mathrm{PW}\end{array}$ & 5.6 & - & \\
\hline
\end{tabular}

\subsection{Adsorption isotherms.}

Adsorption isotherms have been studied to analyze adsorption mechanisms and evaluate how adsorbed molecules are distributed in the adsorbent. Three isothermal models were used to determine which of them is the best combination for the adsorption process, Langmuir (Eq. 5), Freundlich (Eq. 6), and Temkin (Eq. 7) models:

$\frac{1}{\mathrm{q}_{\mathrm{e}}}=\frac{1}{\mathrm{q}_{\mathrm{m}}}+\frac{1}{\mathrm{~K}_{\mathrm{L}} \mathrm{C}_{\mathrm{e}} \mathrm{q}_{\mathrm{m}}}$

$\ln \mathrm{q}_{\mathrm{e}}=\frac{1}{\mathrm{n}} \ln \mathrm{C}_{\mathrm{e}}+\mathrm{K}_{\mathrm{F}}$

$\mathrm{q}_{\mathrm{e}}=\mathrm{B} \ln \left(\mathrm{K}_{\mathrm{T}}\right)+\mathrm{B} \ln \left(\mathrm{C}_{\mathrm{e}}\right)$

where, $\mathrm{q}_{\mathrm{e}}\left(\mathrm{mg} \mathrm{g}^{-1}\right)$ and $\mathrm{q}_{\mathrm{m}}\left(\mathrm{mg} \mathrm{g}^{-1}\right)$ represent the balance and the maximum removal amounts of $\mathrm{O} \& \mathrm{G}, \mathrm{C}_{\mathrm{e}}\left(\mathrm{mg} \mathrm{L}^{-1}\right)$ is the $\mathrm{O} \& \mathrm{G}$ equilibrium concentration $\left(\mathrm{mg} \mathrm{g}^{-1}\right) . \mathrm{K}_{\mathrm{L}}$ is the Langmuir adsorption rate constant associated with the adsorption rate $\left(\mathrm{L} \mathrm{mg}^{-1}\right) . \mathrm{K}_{\mathrm{F}}$ is a capacity factor, which indicates solid adsorbent capacity in a specific concentration of a solute, $n$ is an exponential factor, which indicates the Freundlich adsorption index and describes a nonlinear degree of adsorption isotherm. $\mathrm{B}$ is the Temkin adsorption constant related to adsorption heat; $\mathrm{K}_{\mathrm{T}}$ is Temkin isothermal constant $\left(\mathrm{L} \mathrm{mg}^{-1}\right)$. These adjustment results are presented in Table 4.

The Freundlich model was the one that best described the isothermal adsorption data. This model assumes that adsorbents have a heterogeneous distribution of active sites. Interactions occur between adsorbed molecules, therefore, with capture by multiple layers $[47,63]$. The Freundlich model demonstrates that the adsorbed proportion in each adsorbent mass in relation to the solute is not constant at different solution concentrations. First, the strongest binding sites are occupied, and then an exponential decline in adsorption energy occurs [64].

\subsection{Adsorption thermodynamics.}

Thermodynamic parameters were determined to know the temperature effect on the adsorption of oils and greases using AC-Fe. The O\&G thermodynamic parameters adsorption in $\mathrm{AC}-\mathrm{Fe}$ were evaluated based on the distribution coefficient $\mathrm{k}_{\mathrm{d}}$, which is the ratio of the $\mathrm{O} \& \mathrm{G}$ 
residual equilibrium concentration in solution $\mathrm{C}_{\mathrm{e}}\left(\mathrm{mg} \mathrm{L}^{-1}\right)$, by the $\mathrm{O} \& \mathrm{G}$ amount adsorbed in activated carbon in equilibrium qe $\left(\mathrm{mg} \mathrm{g}^{-1}\right)$, Eq. (8).

Table 4. Langmuir, Freundlich and Temkin parameters at different temperatures.

\begin{tabular}{|c|c|c|c|c|}
\hline \multirow{2}{*}{ Adsorbent } & \multirow{2}{*}{$\mathbf{T}(\mathbf{K})$} & \multicolumn{3}{|c|}{ Langmuir isotherm } \\
\hline & & $q_{m}\left(m g ~ g ~^{-1}\right)$ & $\mathrm{K}_{\mathrm{L}}\left(\mathrm{L} \mathrm{mg}^{-1}\right)$ & $\overline{\mathbf{R}^{2}}$ \\
\hline \multirow{13}{*}{$\mathrm{AC}-\mathrm{Fe}$} & 298 & 526.32 & 0.0131 & 0.9925 \\
\hline & 308 & 263.16 & 0.0163 & 0.9932 \\
\hline & 318 & 250.00 & 0.0133 & 0.9839 \\
\hline & \multirow{2}{*}{$\mathrm{T}(\mathrm{K})$} & \multicolumn{3}{|c|}{ Freundlich isotherm } \\
\hline & & $\mathrm{n}$ & $\mathrm{K}_{\mathrm{F}}\left(\mathrm{L} \mathrm{mg}^{-1}\right)$ & $\mathrm{R}^{2}$ \\
\hline & 298 & 1.1531 & 8.0112 & 0.9963 \\
\hline & 308 & 1.4359 & 7.5370 & 0.9969 \\
\hline & 318 & 1.4057 & 5.9679 & 0.9956 \\
\hline & \multirow{2}{*}{$\mathrm{T}(\mathrm{K})$} & \multicolumn{3}{|c|}{ Temkin isotherm } \\
\hline & & B & $\mathrm{K}_{\mathrm{T}}\left(\mathrm{L} \mathrm{mg}^{-1}\right)$ & $\mathrm{R}^{2}$ \\
\hline & 298 & 78.63 & 0.2329 & 0.9169 \\
\hline & 308 & 58.62 & 0.1623 & 0.9542 \\
\hline & 318 & 60.20 & 0.1176 & 0.9134 \\
\hline
\end{tabular}

$k_{d}=q_{e} / C_{e}$

Adsorption-free energy $\left(\Delta \mathrm{G}^{\mathrm{o}}\right)$ can be calculated by Eq. (9):

$\Delta G^{o}=-R T \ln k_{d}$

The enthalpy variation and standard entropy adsorption were evaluated by Eq. (10). $\ln k_{d}=\left(\Delta S^{\circ} / R\right)-\left(\Delta H^{\circ} / R T\right)$

$\mathrm{T}(\mathrm{K})$ is temperature, and $\mathrm{R}\left(8,314 \mathrm{~J} \mathrm{~mol}^{-1} \mathrm{~K}^{-1}\right)$ is the gas molar constant. The O\&G adsorption thermodynamic behavior in the carbons produced was evaluated by thermodynamic parameters, Gibbs energy $\Delta \mathrm{G}^{\mathrm{o}}\left(\mathrm{kJ} \mathrm{mol}^{-1}\right)$, enthalpy variation $\Delta \mathrm{H}^{\mathrm{o}}\left(\mathrm{kJ} \mathrm{mol}^{-1}\right)$, and entropy $\Delta \mathrm{S}^{\mathrm{o}}$ $\left(\mathrm{J} \mathrm{K}^{-1} \mathrm{~mol}^{-1}\right)$. The thermodynamic parameters are summarized in Table 5. Gibbs' negative energy indicates that the adsorption process is spontaneous and thermodynamically favorable under the conditions established in this study $[15,46]$. As the system temperature increases, the absolute values of $\Delta \mathrm{G}$ decrease, suggesting the downward trend of the adsorption process. This indicates that low temperatures provide better adsorption [15]. Negative $\Delta H$ confirms that the phenomenon of O\&G adsorption in AC-Fe is exothermic, which produces a decrease in adsorption capacity when the process temperature increases. Besides, the adsorption properties of activated carbons can be concluded from $\Delta H$ values. According to Gong et al. (2020) [42], when the absolute $\Delta \mathrm{H}$ value is between 20 and $80 \mathrm{~kJ} \mathrm{~mol}^{-1}$, as observed in AC-Fe, it indicates that the physisorption and chemisorption mechanisms can dominate $\mathrm{O} \& \mathrm{G}$ adsorption in mesopore carbons. Physisorption occurs due to weak electrostatic interactions, including London forces, dipole-dipole forces, and Van der Waals interactions, where bands can be easily broken due to weak interactions [64,65]. According to Pintor et al. (2016) [2], many researchers agree that chemisorption occurs between oil and most adsorbent materials. Hydrophobic interactions lead to the adsorption of oil and organics from the aqueous medium by a partitioning process. Negative $\Delta \mathrm{S}$, in turn, indicates a decrease in randomness in the solid/liquid interface in the adsorption studied [15].

Table 5. Activation energy and thermodynamic parameters.

\begin{tabular}{c|c|c|c|c} 
Activated carbon & $\mathbf{T}(\mathbf{K})$ & $\boldsymbol{\Delta} \mathbf{G}\left(\mathbf{k J ~ m o l}^{-\mathbf{1}}\right)$ & $\boldsymbol{\Delta} \mathbf{H}\left(\mathbf{k J ~ m o l}^{-\mathbf{1}}\right)$ & $\boldsymbol{\Delta} \mathbf{S}\left(\mathbf{J ~ K}^{-\mathbf{1}} \mathbf{~ m o l}^{-\mathbf{1}}\right)$ \\
\hline \multirow{3}{*}{$\mathrm{AC}-\mathrm{Fe}$} & 298 & -4.195 & & \\
\cline { 2 - 3 } & 308 & -2.232 & \multirow{2}{*}{-41.84} & -126.99 \\
\cline { 2 - 3 } & 318 & -1.687 & &
\end{tabular}




\subsection{Adsorbent regeneration.}

The reuse of carbons after desorption and regeneration is particularly important to decrease the cost of the adsorbent. To estimate the AC-Fe reuse efficacy, the worn adsorbent's regeneration was studied using distilled water and a $0.1 \mathrm{M}$ solution of $\mathrm{HCl}$, as shown in Fig. 10. For AC-Fe, there was a significant decrease in adsorption capacity already in the 1 st cycle of use, using distilled water or $\mathrm{HCl}$ solution, possibly due to the blockade of active sites present on the carbon surface and changes in the adsorbent chemistry and structure. The \% removal in the 1 st cycle by the recycled AC-Fe was close to $66 \%$ for distilled water and $59 \%$ for $\mathrm{HCl}$. Perhaps, a promising way to improve AC-Fe's reuse is iron impregnation before carbonization, rather than modification of the finished carbon surface. Gong et al. (2020) [42] showed that iron impregnation before carbonization is a very promising way to improve carbon reuse.

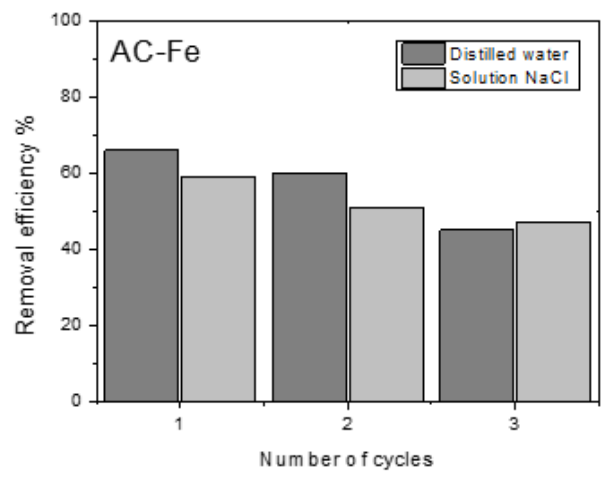

Figure 10. Regeneration of AC-Fe.

\section{Conclusions}

The AC-Fe functionalization with iron nanoparticles was successful. SEM and FTIR demonstrated that the nanoparticles were retained in the developed material and the Boehm method confirms that the AC impregnation with iron altered the surface groups. Adsorption studies revealed that AC-Fe effectively removed $94.2 \%$ of O\&G from PW. The nitrogen adsorption isotherm for AC-Fe was a characteristic of substantially mesoporous material. The pseudo-second-order model was the one that best represented the kinetic data. For the equilibrium data, the Freundlich model was the one that best correlated, indicating the multilayer adsorption mechanism. The thermodynamic parameters indicated a spontaneous and exothermic process. AC-Fe showed that the iron impregnation's main advantage is the catalytic properties optimization. However, further research in the leaching of metals impregnated in AC should be carried out to ensure the process viability.

\section{Funding}

This research was funded by "Fundação de Amparo à Pesquisa do Estado da Bahia", grant number BOL2575/2016".

\section{Acknowledgments}

We thank the Laboratory of Alternative Technologies of the Federal University of Sergipe and the Catalysis and Environment Group (CATAM) of UNIFACS/UFBA. This work was supported by the Foundation for Research Support of the State of Bahia (FAPESB). 


\section{Conflicts of Interest}

\section{The authors declare no conflict of interest.}

\section{References}

1. Al-Salmi, M.; Laqbaqbi, M.; Al-Obaidani, S.; Al-Maamari, R.S.; Khayet, M.; Al-Abri, M. Application of membrane distillation for the treatment of oil field produced water. Desalination 2020, 494, 114678, https://doi.org/10.1016/j.desal.2020.114678.

2. Pintor, A.M.A.; Vilar, V.J.P.; Botelho, C.M.S.; Boaventura, R.A.R. Oil and grease removal from wastewaters: Sorption treatment as an alternative to state-of-the-art technologies. A critical review. Chem. Eng. J. 2016, 297, 229-255, https://doi.org/10.1016/J.CEJ.2016.03.121.

3. Menkiti, M.; Ezemagu, I.; Singaraju, S. Focus on adsorptive equilibrium, kinetics and thermodynamic components of petroleum produced water biocoagulation using novel Tympanotonos Fuscatus extract. Petroleum 2018, 4, 56-64, https://doi.org/10.1016/j.petlm.2017.09.005.

4. Roques, H.; Aurelle, Y. Oil-Water Separations Oil Recovery and Oily Wastewater Treatment. In New Developments in Industrial Wastewater Treatment, Türkman, A., Uslu, O., Eds. Springer Netherlands: Dordrecht, 1991, https://doi.org/10.1007/978-94-011-3272-5_12.

5. Ministério do Meio Ambiente. Conselho Nacional do Meio Ambiente - CONAMA, Resolução $n^{\circ} 393$ 2007, Brasil. Available online: http://rodadas.anp.gov.br/arquivos/Round9/perfuracao_R9/Legisla\%C3\%A7\%C3\%A3o/Resolu\%C3\%A7 \%C3\%A3o\%20CONAMA\%20393-07.pdf.

6. Abdel-Shafy, H.I.; Mansour, M.S.M.; El-Toony, M.M. Integrated treatment for oil free petroleum produced water using novel resin composite followed by microfiltration. Sep. Purif. Technol. 2020, 234, 116058.

7. Chow, H.; Pham, A.L.-T. Effective removal of silica and sulfide from oil sands thermal in-situ produced water by electrocoagulation. J. Hazard. Mater. 2019, 380, 120880, https://doi.org/10.1016/J.JHAZMAT.2019.120880.

8. Wang, C.; Wang, Z.; Wei, X.; Li, X. A numerical study and flotation experiments of bicyclone column flotation for treating of produced water from ASP flooding. Journal of Water Process Engineering 2019, 32, 100972, https://doi.org/10.1016/J.JWPE.2019.100972.

9. Ding, C.; Zhang, X.; Xiong, S.; Shen, L.; Yi, M.; Liu, B.; Wang, Y. Organophosphonate draw solution for produced water treatment with effectively mitigated membrane fouling via forward osmosis. J. Membr. Sci. 2020, 593, 117429, https://doi.org/10.1016/J.MEMSCI.2019.117429.

10. Lu, H.; Liu, Y.-q.; Cai, J.-b.; Xu, X.; Xie, L.-s.; Yang, Q.; Li, Y.-X.; Zhu, K. Treatment of offshore oily produced water: Research and application of a novel fibrous coalescence technique. Journal of Petroleum Science and Engineering 2019, 178, 602-608, https://doi.org/10.1016/J.PETROL.2019.03.025.

11. Nadella, M.; Sharma, R.; Chellam, S. Fit-for-purpose treatment of produced water with iron and polymeric coagulant for reuse in hydraulic fracturing: Temperature effects on aggregation and high-rate sedimentation. Water Res. 2020, 170, 115330, https://doi.org/10.1016/J.WATRES.2019.115330.

12. Waisi, B.I.; Arena, J.T.; Benes, N.E.; Nijmeijer, A.; McCutcheon, J.R. Activated carbon nanofiber nonwoven for removal of emulsified oil from water. Microporous Mesoporous Mater. 2020, 296, 109966, https://doi.org/10.1016/J.MICROMESO.2019.109966.

13. Yin, Y.B.; Heck, K.N.; Coonrod, C.L.; Powell, C.D.; Guo, S.; Reynolds, M.A.; Wong, M.S. PdAu-catalyzed oxidation through in situ generated $\mathrm{H} 2 \mathrm{O} 2$ in simulated produced water. Catal. Today 2020, 339, 362-370, https://doi.org/10.1016/J.CATTOD.2019.05.001.

14. Zhou, L.; Yu, Q.; Cui, Y.; Xie, F.; Li, W.; Li, Y.; Chen, M. Adsorption properties of activated carbon from reed with a high adsorption capacity. Ecol. Eng. 2017, 102, 443-450, https://doi.org/10.1016/J.ECOLENG.2017.02.036.

15. Hu, X.; Zhang, H.; Sun, Z. Adsorption of low concentration ceftazidime from aqueous solutions using impregnated activated carbon promoted by Iron, Copper and Aluminum. Appl. Surf. Sci. 2017, 392, 332341, https://doi.org/10.1016/j.apsusc.2016.09.047.

16. Altmann, J.; Rehfeld, D.; Träder, K.; Sperlich, A.; Jekel, M. Combination of granular activated carbon adsorption and deep-bed filtration as a single advanced wastewater treatment step for organic micropollutant and phosphorus removal. Water Res. 2016, 92, 131-139, https://doi.org/10.1016/j.watres.2016.01.051.

17. Guillossou, R.; Le Roux, J.; Mailler, R.; Vulliet, E.; Morlay, C.; Nauleau, F.; Gasperi, J.; Rocher, V. Organic micropollutants in a large wastewater treatment plant: What are the benefits of an advanced treatment by activated carbon adsorption in comparison to conventional treatment? Chemosphere 2019, 218, 1050-1060, https://doi.org/10.1016/j.chemosphere.2018.11.182.

18. Perrich, J.R. Activated carbon adsorption for wastewater treatment; CRC press: 2018, https://doi.org/10.1201/9781351069465.

19. Queiroz, L.S.; de Souza, L.K.C.; Thomaz, K.T.C.; Leite Lima, E.T.; da Rocha Filho, G.N.; do Nascimento, L.A.S.; de Oliveira Pires, L.H.; Faial, K.d.C.F.; da Costa, C.E.F. Activated carbon obtained from amazonian biomass tailings (acai seed): Modification, characterization, and use for removal of metal ions from water. 
J. Environ. Manage. 2020, 270, 110868, https://doi.org/10.1016/j.jenvman.2020.110868.

20. Bhatnagar, A.; Hogland, W.; Marques, M.; Sillanpää, M. An overview of the modification methods of activated carbon for its water treatment applications. Chem. Eng. J. 2013, 219, 499-511, https://doi.org/10.1016/J.CEJ.2012.12.038.

21. Ukanwa, K.S.; Patchigolla, K.; Sakrabani, R.; Anthony, E.; Mandavgane, S. A review of chemicals to produce activated carbon from agricultural waste biomass. Sustainability 2019, 11, 6204, https://doi.org/10.3390/su11226204.

22. Hao, Z.; Wang, C.; Yan, Z.; Jiang, H.; Xu, H. Magnetic particles modification of coconut shell-derived activated carbon and biochar for effective removal of phenol from water. Chemosphere 2018, 211, 962-969, https://doi.org/10.1016/j.chemosphere.2018.08.038.

23. Tsoncheva, T.; Mileva, A.; Tsyntsarski, B.; Paneva, D.; Spassova, I.; Kovacheva, D.; Velinov, N.; Karashanova, D.; Georgieva, B.; Petrov, N. Activated carbon from Bulgarian peach stones as a support of catalysts for methanol decomposition. Biomass Bioenergy 2018, 109, 135-146, https://doi.org/10.1016/J.BIOMBIOE.2017.12.022.

24. Choong, C.E.; Wong, K.T.; Jang, S.B.; Nah, I.W.; Choi, J.; Ibrahim, S.; Yoon, Y.; Jang, M. Fluoride removal by palm shell waste based powdered activated carbon vs. functionalized carbon with magnesium silicate: Implications for their application in water treatment. Chemosphere 2020, 239, 124765, https://doi.org/10.1016/J.CHEMOSPHERE.2019.124765.

25. Zhang, Y.; Song, X.; Zhang, P.; Gao, H.; Ou, C.; Kong, X. Production of activated carbons from four wastes via one-step activation and their applications in $\mathrm{Pb} 2+$ adsorption: Insight of ash content. Chemosphere 2020, 245, 125587, https://doi.org/10.1016/J.CHEMOSPHERE.2019.125587.

26. Pena, J.; Villot, A.; Gerente, C. Pyrolysis chars and physically activated carbons prepared from buckwheat husks for catalytic purification of syngas. Biomass Bioenergy 2020, 132, 105435, https://doi.org/10.1016/J.BIOMBIOE.2019.105435.

27. Guo, Y.; Tan, C.; Sun, J.; Li, W.; Zhang, J.; Zhao, C. Porous activated carbons derived from waste sugarcane bagasse for CO2 adsorption. Chem. Eng. J. 2020, 381, 122736, https://doi.org/10.1016/J.CEJ.2019.122736.

28. Rahman, A.; Hango, H.J.; Daniel, L.S.; Uahengo, V.; Jaime, S.J.; Bhaskaruni, S.V.H.S.; Jonnalagadda, S.B. Chemical preparation of activated carbon from Acacia erioloba seed pods using $\mathrm{H} 2 \mathrm{SO} 4$ as impregnating agent for water treatment: An environmentally benevolent approach. Journal of Cleaner Production 2019, 237, 117689, https://doi.org/10.1016/J.JCLEPRO.2019.117689.

29. Moralı, U.; Demiral, H.; Şensöz, S. Optimization of activated carbon production from sunflower seed extracted meal: Taguchi design of experiment approach and analysis of variance. Journal of Cleaner Production 2018, 189, 602-611, https://doi.org/10.1016/J.JCLEPRO.2018.04.084.

30. Sulaiman, N.S.; Hashim, R.; Mohamad Amini, M.H.; Danish, M.; Sulaiman, O. Optimization of activated carbon preparation from cassava stem using response surface methodology on surface area and yield. Journal of Cleaner Production 2018, 198, 1422-1430, https://doi.org/10.1016/J.JCLEPRO.2018.07.061.

31. Santos, T.M.; de Jesus, F.A.; da Silva, G.F.; Pontes, L.A.M. Synthesis of activated carbon from oleifera moringa for removal of oils and greases from the produced water. Environmental Nanotechnology, Monitoring \& Management 2020, 14, 100357, https://doi.org/10.1016/j.enmm.2020.100357.

32. Bakhta, S.; Sadaoui, Z.; Lassi, U.; Romar, H.; Kupila, R.; Vieillard, J. Performances of metals modified activated carbons for fluoride removal from aqueous solutions. Chem. Phys. Lett. 2020, 754, 137705, https://doi.org/10.1016/j.cplett.2020.137705.

33. Cheng, S.; Zhang, L.; Ma, A.; Xia, H.; Peng, J.; Li, C.; Shu, J. Comparison of activated carbon and iron/cerium modified activated carbon to remove methylene blue from wastewater. Journal of Environmental Sciences 2018, 65, 92-102, https://doi.org/10.1016/j.jes.2016.12.027.

34. Hassan, A.F.; Elhadidy, H.; Abdel-Mohsen, A.M. Adsorption and photocatalytic detoxification of diazinon using iron and nanotitania modified activated carbons. Journal of the Taiwan Institute of Chemical Engineers 2017, 75, 299-306, https://doi.org/10.1016/j.jtice.2017.03.026.

35. Jalilvand, H.; Feyzi, F.; Dehghani, M.R. Adsorption of dimethyl sulfide from model fuel on raw and modified activated carbon from walnut and pistachio shell origins: Kinetic and thermodynamic study. Colloids Surf. Physicochem. Eng. Aspects 2020, 593, 124620, https://doi.org/10.1016/J.COLSURFA.2020.124620.

36. Tsoncheva, T.; Velinov, N.; Ivanova, R.; Stoycheva, I.; Tsyntsarski, B.; Spassova, I.; Paneva, D.; Issa, G.; Kovacheva, D.; Genova, I.; Mitov, I.; Petrov, N. Formation of catalytic active sites in iron modified activated carbons from agriculture residues. Microporous Mesoporous Mater. 2015, 217, 87-95, https://doi.org/10.1016/j.micromeso.2015.06.008

37. Xiong, W.; Tong, J.; Yang, Z.; Zeng, G.; Zhou, Y.; Wang, D.; Song, P.; Xu, R.; Zhang, C.; Cheng, M. Adsorption of phosphate from aqueous solution using iron-zirconium modified activated carbon nanofiber: Performance and mechanism. J. Colloid Interface Sci. 2017, 493, 17-23, https://doi.org/10.1016/j.jcis.2017.01.024.

38. Boehm, H.P. Surface oxides on carbon and their analysis: a critical assessment. Carbon 2002, 40, 145-149, https://doi.org/10.1016/S0008-6223(01)00165-8.

39. Oickle, A.M.; Goertzen, S.L.; Hopper, K.R.; Abdalla, Y.O.; Andreas, H.A. Standardization of the Boehm 
titration: Part II. Method of agitation, effect of filtering and dilute titrant. Carbon 2010, 48, 3313-3322, https://doi.org/10.1016/J.CARBON.2010.05.004.

40. Mueller, G.; Radke, C.J.; Prausnitz, J.M. Adsorption of weak organic electrolytes from aqueous solution on activated carbon. Effect of $\mathrm{pH}$. The Journal of Physical Chemistry 1980, 84, 369-376, https://doi.org/10.1021/j100441a006.

41. Kallel, F.; Chaari, F.; Bouaziz, F.; Bettaieb, F.; Ghorbel, R.; Chaabouni, S.E. Sorption and desorption characteristics for the removal of a toxic dye, methylene blue from aqueous solution by a low cost agricultural by-product. J. Mol. Liq. 2016, 219, 279-288, https://doi.org/10.1016/j.molliq.2016.03.024.

42. Gong, X.-J.; Li, Y.-S.; Dong, Y.-Q.; Li, W.-G. Arsenic adsorption by innovative iron/calcium in-situimpregnated mesoporous activated carbons from low-temperature water and effects of the presence of humic acids. Chemosphere 2020, 250, 126275, https://doi.org/10.1016/J.CHEMOSPHERE.2020.126275.

43. Das, S.; Mishra, S. Insight into the isotherm modelling, kinetic and thermodynamic exploration of iron adsorption from aqueous media by activated carbon developed from Limonia acidissima shell. Mater. Chem. Phys. 2020, 245, 122751, https://doi.org/10.1016/J.MATCHEMPHYS.2020.122751.

44. Shen, Y.; Zhou, Y.; Fu, Y.; Zhang, N. Activated carbons synthesized from unaltered and pelletized biomass wastes for bio-tar adsorption in different phases. Renewable Energy 2020, 146, 1700-1709, https://doi.org/10.1016/J.RENENE.2019.07.167.

45. Vunain, E.; Kenneth, D.; Biswick, T. Synthesis and characterization of low-cost activated carbon prepared from Malawian baobab fruit shells by $\mathrm{H} 3 \mathrm{PO} 4$ activation for removal of $\mathrm{Cu}(\mathrm{II})$ ions: equilibrium and kinetics studies. Applied Water Science 2017, 7, 4301-4319, https://doi.org/10.1007/s13201-017-0573-X.

46. Tonucci, M.C.; Gurgel, L.V.A.; Aquino, S.F.d. Activated carbons from agricultural byproducts (pine tree and coconut shell), coal, and carbon nanotubes as adsorbents for removal of sulfamethoxazole from spiked aqueous solutions: Kinetic and thermodynamic studies. Industrial Crops and Products 2015, 74, 111-121, https://doi.org/10.1016/J.INDCROP.2015.05.003.

47. Wang, J.; Zhang, W.; Kang, X.; Zhang, C. Rapid and efficient recovery of silver with nanoscale zerovalent iron supported on high performance activated carbon derived from straw biomass. Environ. Pollut. 2019, 255, 113043, https://doi.org/10.1016/J.ENVPOL.2019.113043.

48. Anjum, H.; Johari, K.; Gnanasundaram, N.; Appusamy, A.; Thanabalan, M. Impact of surface modification on adsorptive removal of BTX onto activated carbon. J. Mol. Liq. 2019, 280, 238-251, https://doi.org/10.1016/j.molliq.2019.02.046.

49. de Oliveira Pereira, L.; Marques Sales, I.; Pereira Zampiere, L.; Silveira Vieira, S.; do Rosário Guimarães, I.; Magalhães, F. Preparation of magnetic photocatalysts from TiO2, activated carbon and iron nitrate for environmental remediation. J. Photochem. Photobiol. A: Chem. 2019, 382, 111907, https://doi.org/10.1016/J.JPHOTOCHEM.2019.111907.

50. Xu, Z.; Tian, D.; Sun, Z.; Zhang, D.; Zhou, Y.; Chen, W.; Deng, H. Highly porous activated carbon synthesized by pyrolysis of polyester fabric wastes with different iron salts: Pore development and adsorption behavior. Colloids Surf. Physicochem. Eng. Aspects 2019, 565, 180-187, https://doi.org/10.1016/J.COLSURFA.2019.01.007.

51. Hu, Z.; Srinivasan, M.P. Mesoporous high-surface-area activated carbon. Microporous Mesoporous Mater. 2001, 43, 267-275, https://doi.org/10.1016/S1387-1811(00)00355-3.

52. Chiang, H.-L.; Huang, C.P.; Chiang, P.C. The surface characteristics of activated carbon as affected by ozone and alkaline treatment. Chemosphere 2002, 47, 257-265, https://doi.org/10.1016/S0045-6535(01)00215-6.

53. Mowla, D.; Karimi, G.; Salehi, K. Modeling of the adsorption breakthrough behaviors of oil from salty waters in a fixed bed of commercial organoclay/sand mixture. Chem. Eng. J. 2013, 218, 116-125, https://doi.org/10.1016/j.cej.2012.12.028.

54. Shaarani, F.W.; Hameed, B.H. Ammonia-modified activated carbon for the adsorption of 2,4dichlorophenol. Chem. Eng. J. 2011, 169, 180-185, https://doi.org/10.1016/J.CEJ.2011.03.002.

55. Dąbrowski, A.; Podkościelny, P.; Hubicki, Z.; Barczak, M. Adsorption of phenolic compounds by activated $\begin{array}{lllll}\text { carbon-a critical } & \text { review. } & \text { Chemosphere }\end{array}$ https://doi.org/10.1016/J.CHEMOSPHERE.2004.09.067

56. Acosta, R.; Nabarlatz, D.; Sánchez-Sánchez, A.; Jagiello, J.; Gadonneix, P.; Celzard, A.; Fierro, V. Adsorption of Bisphenol A on $\mathrm{KOH}$-activated tyre pyrolysis char. Journal of Environmental Chemical Engineering 2018, 6, 823-833, https://doi.org/10.1016/j.jece.2018.01.002.

57. Cheng, W.; Dastgheib, S.A.; Karanfil, T. Adsorption of dissolved natural organic matter by modified activated carbons. Water Res. 2005, 39, 2281-2290, https://doi.org/10.1016/J.WATRES.2005.01.031.

58. Dastgheib, S.A.; Karanfil, T.; Cheng, W. Tailoring activated carbons for enhanced removal of natural organic matter from natural waters. Carbon 2004, 42, 547-557, https://doi.org/10.1016/J.CARBON.2003.12.062.

59. Ewis, D.; Benamor, A.; Ba-Abbad, M.M.; Nasser, M.; El-Naas, M.; Qiblawey, H. Removal of Oil Content from Oil-Water Emulsions Using Iron Oxide/Bentonite Nano Adsorbents. Journal of Water Process Engineering 2020, 38, 101583, https://doi.org/10.1016/j.jwpe.2020.101583.

60. Abou Chacra, L.; Sabri, M.A.; Ibrahim, T.H.; Khamis, M.I.; Hamdan, N.M.; Al-Asheh, S.; AlRefai, M.; Fernandez, C. Application of graphene nanoplatelets and graphene magnetite for the removal of emulsified oil from produced water. Journal of Environmental Chemical Engineering 2018, 6, 3018-3033, 
https://doi.org/10.1016/j.jece.2018.04.060.

61. Lin, K.-Y.A.; Chen, Y.-C.; Phattarapattamawong, S. Efficient demulsification of oil-in-water emulsions using a zeolitic imidazolate framework: Adsorptive removal of oil droplets from water. J. Colloid Interface Sci. 2016, 478, 97-106, https://doi.org/10.1016/j.jcis.2016.05.057.

62. Gallo-Cordova, A.; Silva-Gordillo, M.d.M.; Muñoz, G.A.; Arboleda-Faini, X.; Almeida Streitwieser, D. Comparison of the adsorption capacity of organic compounds present in produced water with commercially obtained walnut shell and residual biomass. Journal of Environmental Chemical Engineering 2017, 5, 40414050, https://doi.org/10.1016/j.jece.2017.07.052. https://doi.org/10.1016/j.jece.2017.07.052.

63. Piccin, J.; Dotto, G.; Pinto, L. Adsorption isotherms and thermochemical data of FDandC RED N N $^{\circ}$ Binding by chitosan. Brazilian Journal of Chemical Engineering 2011, 28, 295-304, https://doi.org/10.1590/S010466322011000200014.

64. Al-Ghouti, M.A.; Da'ana, D.A. Guidelines for the use and interpretation of adsorption isotherm models: A review. J. Hazard. Mater. 2020, 393, 122383, https://doi.org/10.1016/J.JHAZMAT.2020.122383.

65. Mushtaq, M.; Bhatti, H.N.; Iqbal, M.; Noreen, S. Eriobotrya japonica seed biocomposite efficiency for copper adsorption: Isotherms, kinetics, thermodynamic and desorption studies. J. Environ. Manage. 2016, 176, 21-33, https://doi.org/10.1016/J.JENVMAN.2016.03.013. 